\title{
VEGETATIVE GROWTH OF UMBRELLA LEAF PALM, JOHANNESTEIJSMANNIA LANCEOLATA IN ANGSI FOREST RESERVE, MALAYSIA
}

\author{
M.Z. Rozainah and U.R. Sinniah* \\ Institute of Biological Sciences \\ University of Malaya, 50603 Kuala Lumpur, Malaysia \\ *Faculty of Agriculture \\ University Putra Malaysia, 46400 Serdang, Selangor, Malaysia
}

\begin{abstract}
A study of an acaulescent palm, Johannesteijsmannia lanceolata J. Dransfield was carried out in Angsi Forest Reserve, Negeri Sembilan, Malaysia for a period of 19 months. A total of 32 adults, 24 juveniles and 32 seedlings from 3 different plots were censused every two-weeks. The results showed that the average numbers of new leaves entering the crown within the study period (19 months) were: $3.3,2.6$ and 1.3 for $2.1,1.6$ and 0.8 leaves per year for adult, juvenile and seedling, respectively. From the calculation, it was discovered that the time spent by each leaf in the crown before it died was 8.8 years for adult and 8.4 years for juvenile.
\end{abstract}

Key words: Johannesteijsmannia, growth rate, vegetative phenology, Arecaceae.

\section{INTRODUCTION}

The study of growth rates of forest species is vital in forest management and regeneration because it indicates how fast or how slow the forest can regenerate and recover, especially after forest disturbance, which is currently being addressed in many developing countries including Malaysia. Especially in the case of the species studied here, which has been classified as under threat, the data of growth rates is important to emphasise the need for its protection.

There are many different ways to measure and assess the growth of palms, and palms can be ranked by their rates of growth. The results can vary depending on the method used to measure growth. Number of leaves produced, height of the stem, the number of leaves per unit of stem height or simply biomass are all among the methods used in evaluating and comparing the growth of palms.
In this research, the authors have chosen to estimate the growth by determining the number of leaves produced in a given period. In palms, each stem ends in a leafy crown made up of leaves produced singly in succession. The earliest stage of the leaf is not visible because it is enclosed and concealed by older developing leaves. It becomes visible as a slender spike growing from the centre of the crown, with the various parts of the future blade folded together. The spike elongates and the blade then opens quite quickly as the leaf becomes mature, revealing the whole leaf. Leaf development in palms is best studied by examining the sec'uences of leaves in the crown because it is virtually impossible to follow the changes in a specific leaf as it develops. Each leaf in the sequence is then interpreted as representing a step in leaf development. The interval between the production of two successive leaves is termed the 
'plastochrone'. In this study, the plastochrone is used to calculate the lifespan of a single leaf, i.e., a period between a single leaf entering the crown and its death, with this simple calculation:

Leaf life span; LLS = PL x CL;

Where, $\mathrm{PL}=$ plastochrone and $\mathrm{CL}=$ total number of leaves in crown.

The formula can be used with the assumption that the plastochrone interval is constant, but knowing the exact interval requires a long period of field observation. However, it has been proven that palm growth rates are almost constant, and short-term measurements do reflect overall growth rates accurately (Sarukhan 1978).

This paper examines the growth rate of umbrella leaf palm, Johannesteijsmannia lanceolata in Angsi Forest Reserve, Negeri Sembilan, Malaysia. J. lanceolata is a solitary, pleonanthic, acaulescent and hermaphrodite palm which belongs to the subfamily Coryphoideae (Uhl and Dransfield 1987). It is a plant of hill slopes, in the undergrowth of primary rain forest, and is very intolerant of forest disturbance. It has never been observed in secondary forest and rarely survives any clear felling (Dransfield 1972). J. lanceolata is one of the four Johannesteijsmannia species that are classified as rare and under threat (Johnson 1996). This genus can be found in the north Sumatra, Malay Peninsular and Borneo (Dransfield 1972). Johannesteijsmannia (with exception of $J$. perakensis) lacks a visible stem, so that the leaves appear from the ground. They have large, simple, undivided leaves that can reach a length of more than $6 \mathrm{~m}$, rising directly from an underground rootstock. These exceptionally large leaves, varying from roughly diamond-shaped to broadly lanceolate in shape, are pleated along their length, giving a most bizarre appearance and the local name 'umbrella leaf palm' in some parts of the Malay Peninsular. Other local names used are sal or tal or koh. Leaf sheaths are short and break down into a fibrous, interwoven mass as they age. Petioles are armed with small and sharp spines. The inflorescences arise among the leaves. The species studied $J$. lanceolata is identified based on its narrow leaves and its inflorescence structure which bear about 6-8 branches.

\section{STUDY SITE}

$\mathrm{J}$. lanceolata occurs in a quite substantial numbers at Angsi Forest Reserve, about $20 \mathrm{~km}$ from the town of Seremban, the capital of Negeri Sembilan. The location is $\mathrm{N} 2^{\circ} 43^{\prime} 39.5^{\prime \prime}$ and $\mathrm{E}$ $102^{\circ} 4^{\prime} 40.9^{\prime \prime}$ at $185 \mathrm{~m}$ elevation. The forest reserve is classified as a dipterocarp forest and is adjacent to Ulu Bendul Recreational Park. The species can be found at elevation of around $200 \mathrm{~m}$ above sea level on the hill slopes on both sides along the Batang Terachi river which runs from the mountain to the recreational park.

The nearest meteorological station is at Port Dickson. Temperature during the year is high and uniform, with an annual mean of $28.0^{\circ} \mathrm{C}$. Mean annual rainfall is $2376 \mathrm{~mm}$, distributed fairly evenly throughout the year (Manokaran and Kochummen 1987).

\section{MATERIALS AND METHODS}

Three plots were set up, each of $40 \times 40$. The area chosen contained the greatest concentration of the species, so that they contained enough plants for the study. The plots were laid parallel to the river and were marked at least $5 \mathrm{~m}$ away from the trail along the river to avoid any disturbances from passers by.

In this study, three life stages were differentiated based on the number of living leaves in the crown: seedling (from newly germinated to 9 crown leaves), juvenile (from 10 to 18 crown leaves), and adult (from 19 to 35 crown leaves). 
Each individual of $J$. lanceolata that occurred within the boundary was tagged and numbered in an arbitrary order. To observe their growth rates, a total of 32 adults, 24 juveniles and 32 seedlings in 3 study plots were selected arbitrarily and monitored closely for their leaves developments for a total period of 19 months. At the beginning of the study, the number of crown leaves, the number of dried/dead leaves and their reproductive status was recorded. Then every fortnight, the appearance of new spear leaves entering the crown and their elongations until they were fully opened revealing complete leaves were observed and measured. The mean and variance of the data were calculated using SAS program. Besides this, $t$-test was also used to check the significance of difference in data obtained from different plots.

\section{RESULTS}

The average numbers of crown leaves, numbers of new leaves entering the crown, plastochrone and leaf life span are shown in Table 1. The leaf numbers per plant varied from 19 to 35 for the 32 adults, from 10 to 18 for the 24 juveniles and from 1 to 9 leaves for the 32 seedlings. The average number of leaves was 24 in adults, 15 in juveniles and 4 in seedlings (Table 1).
Table 1. Mean values of average crown leaves (CL), new leaf production (NL), plastochrone (PL) and leaf life span (LLS) of adult, juvenile and seedling.

\begin{tabular}{lccccc}
\hline Stage & CL & NL & $\begin{array}{c}\text { PL } \\
\text { (month) }\end{array}$ & $\begin{array}{c}\text { LLS } \\
\text { (month) }\end{array}$ & $\begin{array}{c}\text { LLS } \\
\text { (year) }\end{array}$ \\
\hline Adult & $24.3^{\text {ns }}$ & $3.3^{\text {ns }}$ & $4.5^{\text {ns }}$ & $106.0^{\text {ns }}$ & $8.8^{\text {ns }}$ \\
Juvenile & $14.8^{\text {ns }}$ & $2.6^{\text {ns }}$ & $6.9^{\text {ns }}$ & $101.5^{\text {ns }}$ & $8.4^{\text {ns }}$ \\
Seedling & $4.1^{\text {ns }}$ & $1.3^{\text {ns }}$ & na & na & na \\
\hline
\end{tabular}

ns $=$ not significant at $5 \%$ level, na $=$ not available.

The results also indicate that the leaf production of each individual rises from an average of 0.8 leaves per year (1.3 leaves per 19 months) in the seedling stage, to 1.6 leaves per year (2.6 leaves per 19 months) in juveniles, and 2.1 leaves per year (3.3 leaves per 19 months) for adults. The plastochrone (interval between the productions of two successive leaves) is 6.9 months for juveniles and 4.5 months for adults.

With the formula LLS = PL X CL, we found that the lifespan of each leaf is 8.8 years in adults and 8.4 years in juveniles. However, the plastochrone for seedlings could not be obtained reliably, due to its very slow growth - a study period of 19 months is not sufficient.

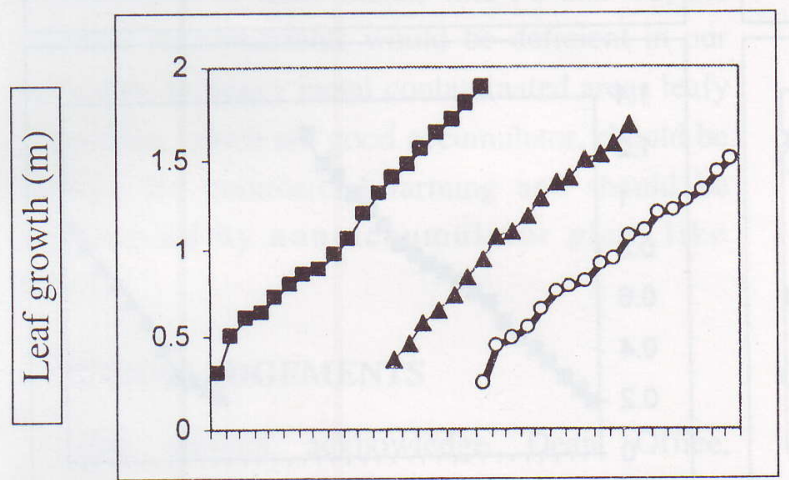

Time (bi-weekly)

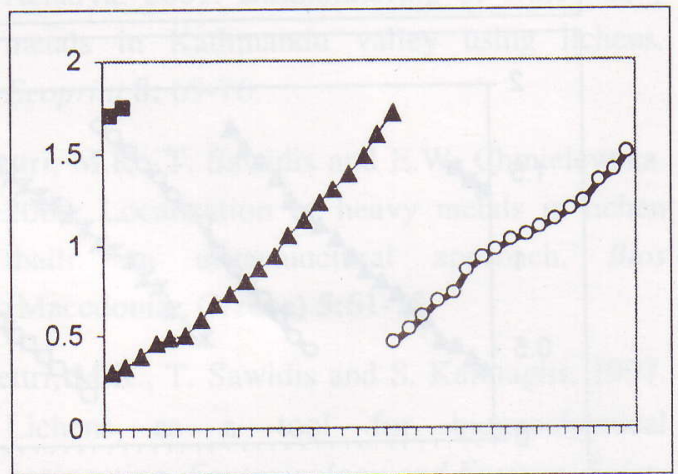

Time (bi-weekly) 


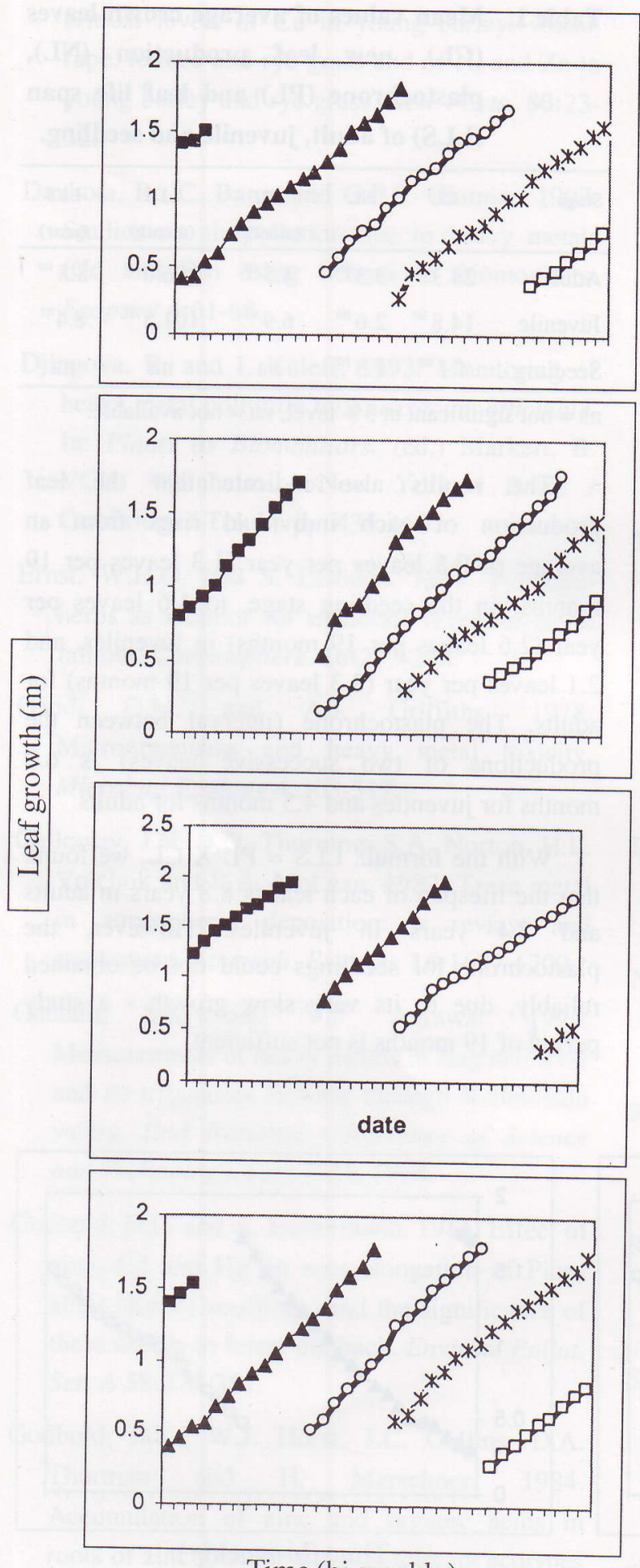

Time (bi-weekly)
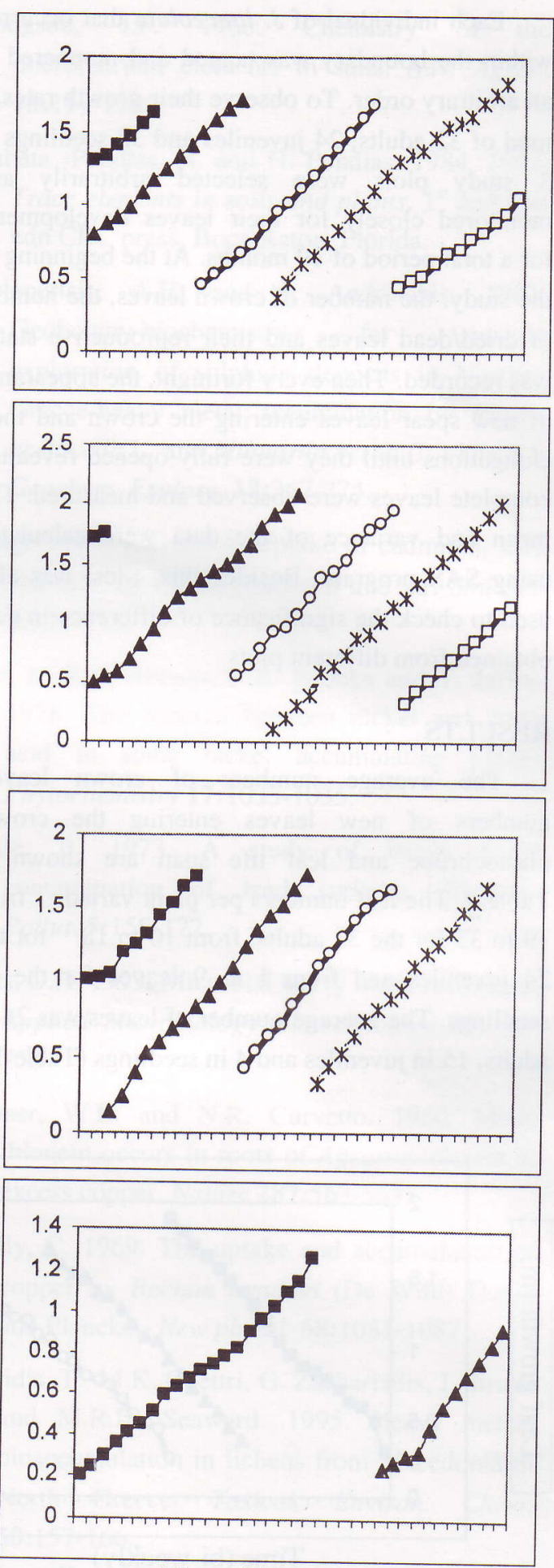

Time (bi-weekly)

Fig. 1. Leaf production in 9 adults of $J$. lanceolata in plot 3 for a period of 19 months. Growth is represented by appearance of spear leaf and its elongation untill a fully opened leaf. 


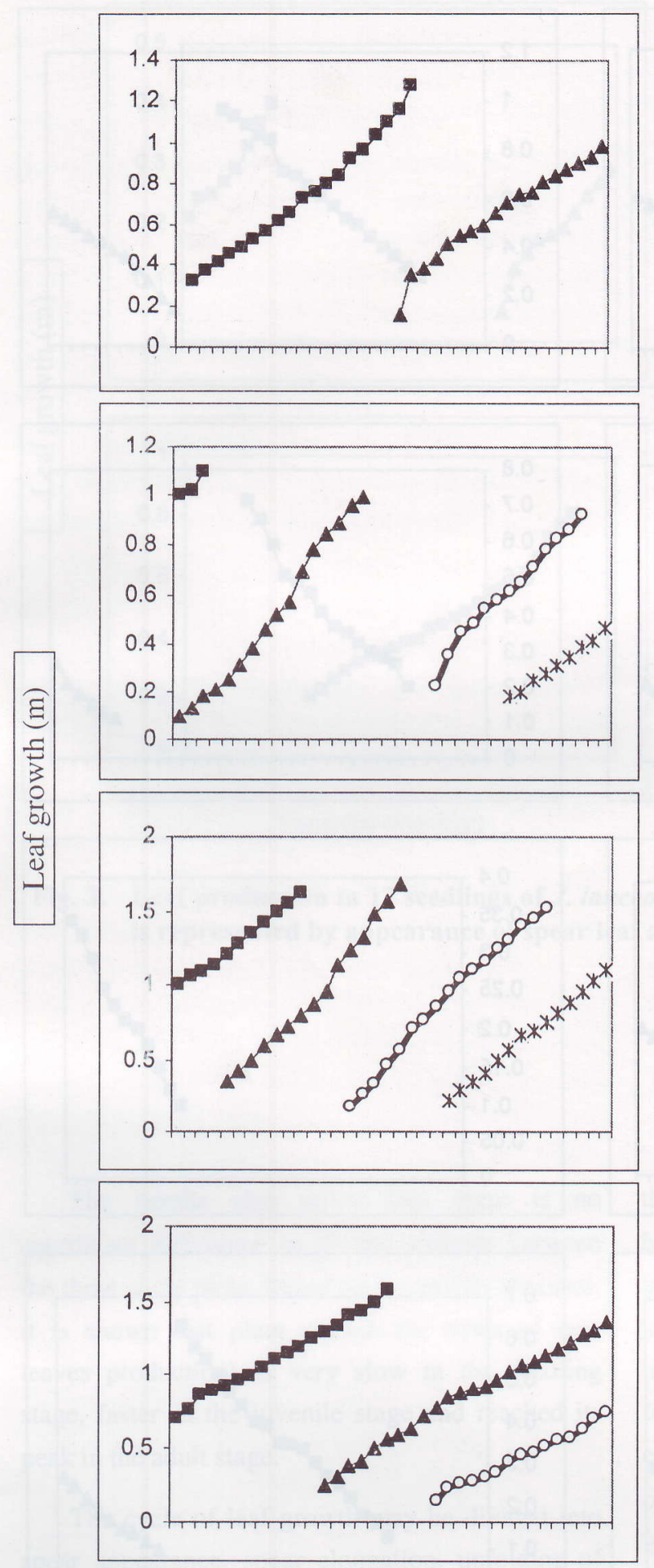

Time (bi-weekly)
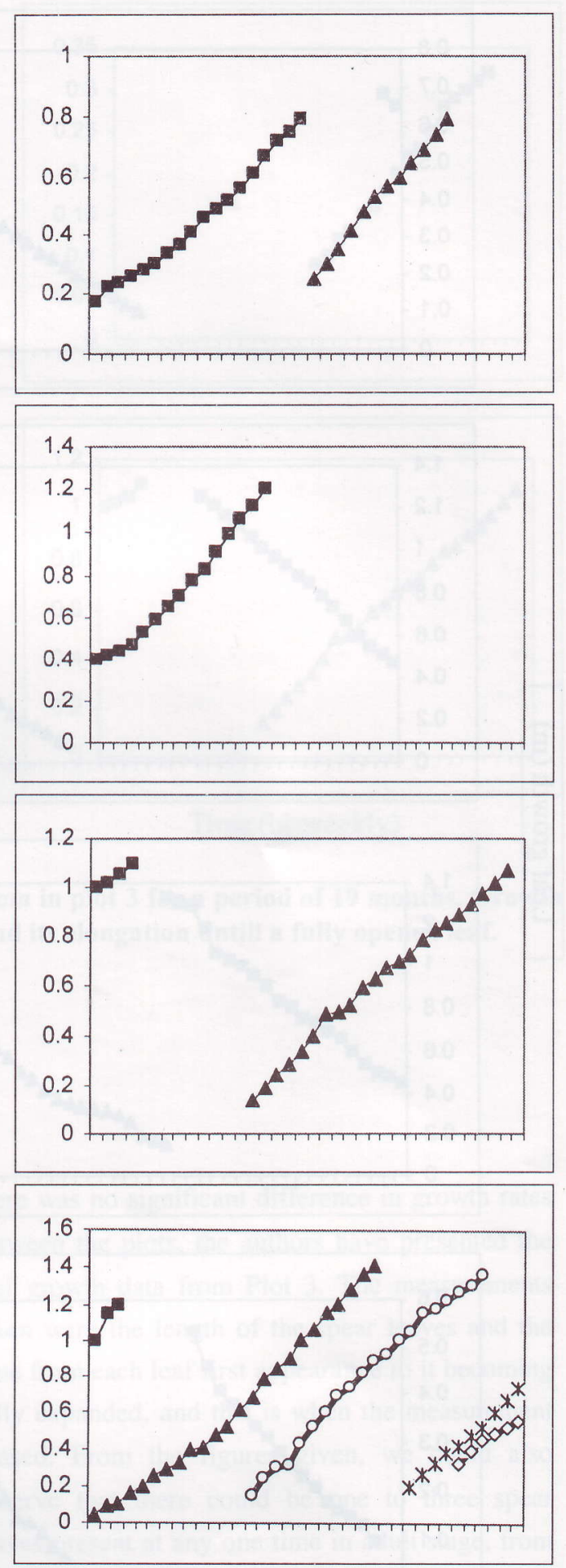

Time (bi-weekly)

Fig. 2. Leaf production in 9 juveniles of $J$. lanceolata in plot 3 for a period of 19 months. Growth is represented by appearance of spear leaf and its elongation untill a fully opened leaf. 

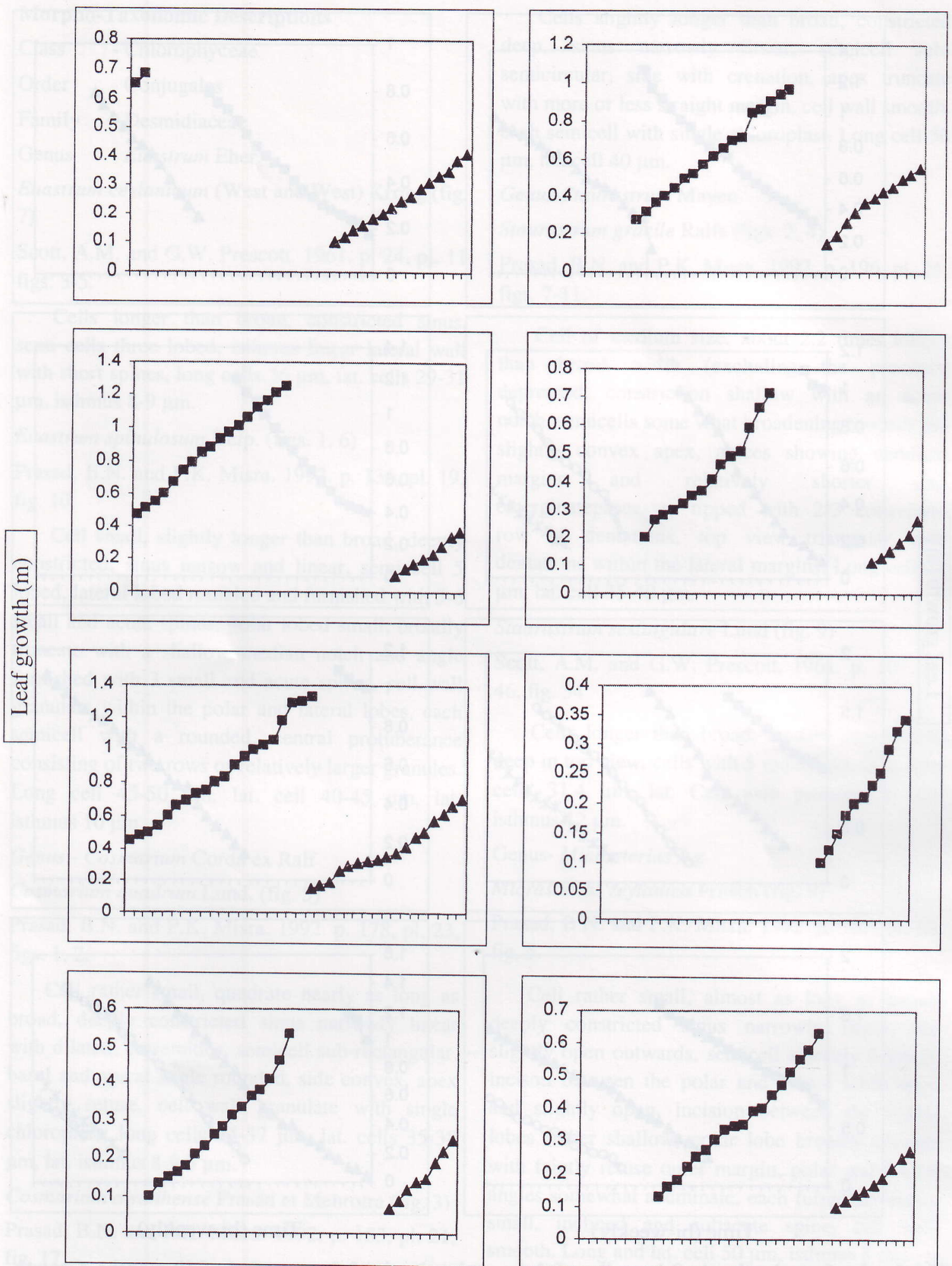

Time (bi-weekly)
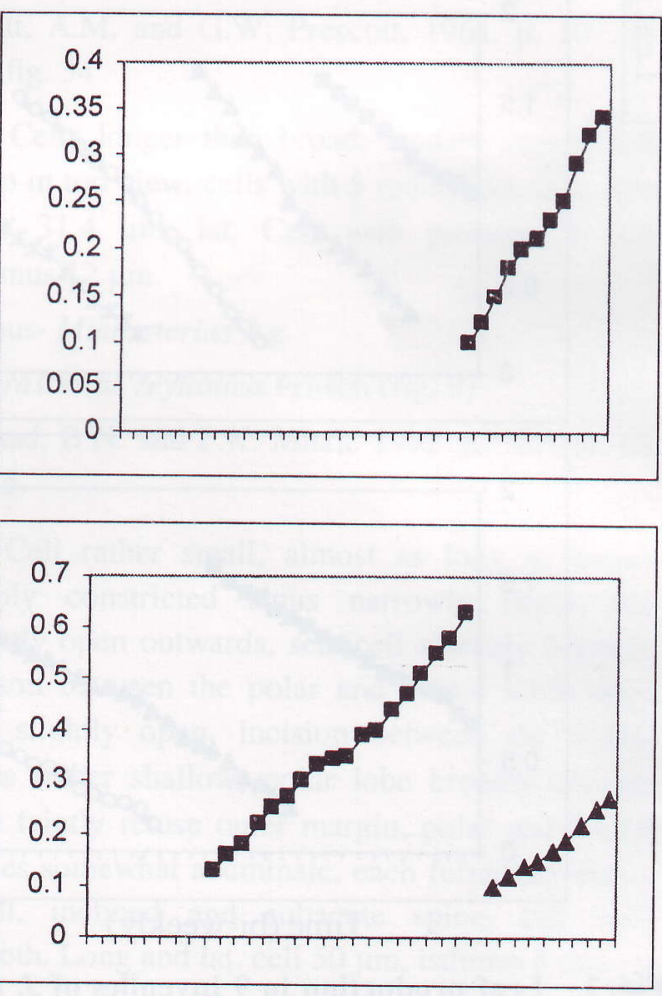

Time (bi-weekly)

ECOPRINT VOL 12, 2005 


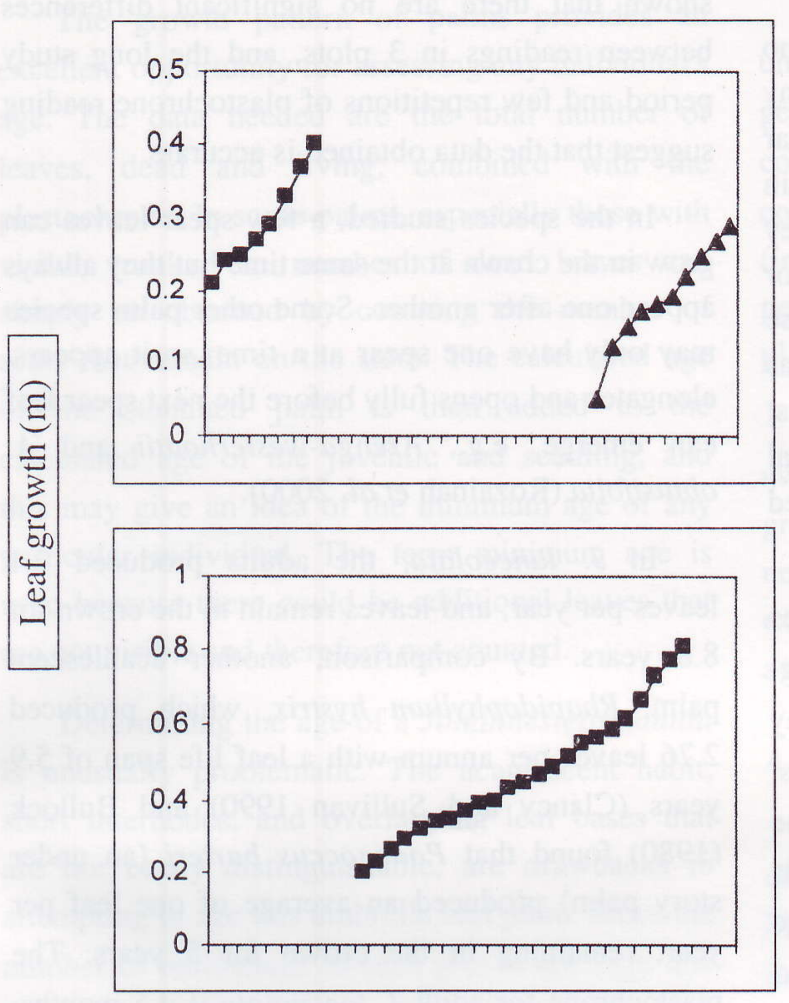

Time (bi-weekly)
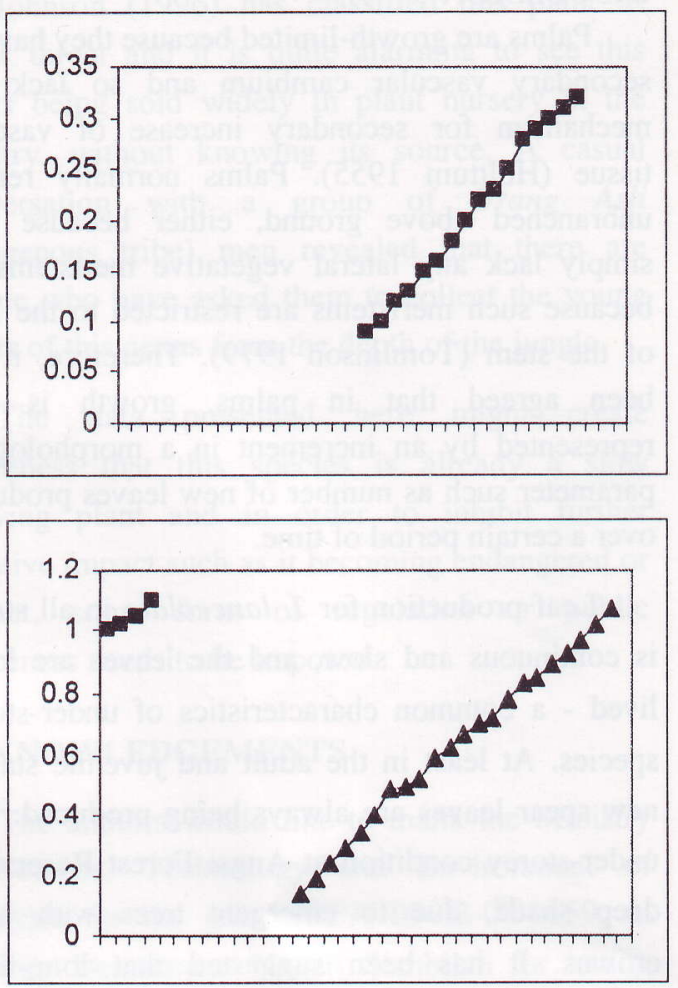

Time (bi-weekly)

Fig. 3. Leaf production in 12 seedlings of $J$. lanceolata in plot 3 for a period of 19 months. Growth is represented by appearance of spear leaf and its elongation untill a fully opened leaf.

The results also prove that there is no significant difference in all the readings between the three study plots. Based on the results obtained, it is shown that plant growth (in terms of new leaves production) is very slow in the seedling stage, faster in the juvenile stage and reached its peak in the adult stage.

The cycle of leaf growth may be divided into spear appearance, spear elongation, unfolding of the spear and the appearance of the next spear leaf. This has been shown in Figures 1, 2 and 3. Since there was no significant difference in growth rates between the plots, the authors have presented the leaf growth data from Plot 3. The measurements taken were the length of the spear leaves and the time from each leaf first appearance to it becoming fully expanded, and this is when the measurement ceased. From the figures given, we could also observe that there could be one to three spear leaves present at any one time in adult stage, from one to two spear leaves in juvenile stage, and only one spear leaf at any one time in the seedling stage. 


\section{DISCUSSION}

Palms are growth-limited because they have no secondary vascular cambium and so lack any mechanism for secondary increase of vascular tissue (Holttum 1955). Palms normally remain unbranched above ground, either because they simply lack any lateral vegetative meristems, or because such meristems are restricted to the base of the stem (Tomlinson 1979). Therefore, it has been agreed that in palms, growth is best represented by an increment in a morphological parameter such as number of new leaves produced over a certain period of time.

Leaf production for J. lanceolata in all stages is continuous and slow, and the leaves are longlived - a common characteristics of under-storey species. At least in the adult and juvenile stages, new spear leaves are always being produced. The under-storey condition at Angsi Forest Reserve is deep shade, due to emergent trees with huge crowns. It has been suggested that long-lived leaves give an advantage in under-storey environments (Kikuzawa 1989) as an adaptation to light restriction.

Leaf life-span is a measurement of how long a single leaf remains in the crown, and this depends on the number of living leaves in the crown. As one leaf enters the crown, another leaf is produced by the apical meristem as the oldest leaf dies (Clancy and Sullivan 1990), and the number of leaves in the crown was approximately equal to the number at the beginning, where no apparent transition series from seedling to juvenile and juvenile to adult were observed in the whole study period. The leaf life span of a larger individual (one with more leaves in the crown) would be expected to be longer, and this is true in our study where the adults' leaves remain the longest time in the crown. In this study, our calculations on leaf life span are based on only 32 and 24 individuals of adults and juveniles respectively, and this may limit their inaccuracy. However, the t-test has shown that there are no significant differences between readings in 3 plots, and the long study period and few repetitions of plastochrone reading suggest that the data obtained is accurate.

In the species studied, a few spear leaves can grow in the crown at the same time but they always appear one after another. Some other palm species may only have one spear at a time; so it appears, elongates and opens fully before the next spear leaf can emerge, e.g., Arenga-westerhoutii and A. obtusifolia (Rozainah et al. 2000).

In $J$. lanceolata, the adults produced 2.1 leaves per year, and leaves remain in the crown for 8.8 years. By comparison, another acaulescent palm, Rhapidophyllum hystrix, which produced 2.76 leaves per annum with a leaf life span of 5.9 years (Clancy and Sullivan 1990) and Bullock (1980) found that Podococcus barteri (an under story palm) produced an average of one leaf per year, remaining in the crown for 5 years. The plastochrone for adult $J$. lanceolata is 4.5 months, indicating the shortest period before the next spear leaf emerges after the unfolding of the previous spear leaf. This implies a rapid growth compared to its younger generations, and leaf production rates vary significantly throughout the plant's life. Juveniles grow slower than adults in this study, as expected and also as found in many other studies (De Steven et al. 1987). Seedlings grow slowest, with not even one full leaf appearing in one year. Because only one new leaf was observed entering each seedling's crown in the whole study period of 19 months, their plastochrone could not be measured (2 successive new leaves must be observed), and this also prevented the calculation of leaf life span. This slowness of growth is attributed to the fact that the seedling slowly builds up an apex of the final size of girth, and hence producing new leaves take a longer time. In adults, there is no allocation of energy to increase the girth size, so more energy can be allocated to produce new leaves. 
The growth pattern of palms provides an excellent opportunity for assessing any individual's age. The data needed are the total number of leaves, dead and living, combined with the plastochrone. In some palms, especially those with visible trunks, the number of dead leaves can simply be obtained by counting the number of scars that remain on the stem. The calculated age of the stemmed palm is then added to the calculated age of the juvenile and seedling, and this may give an idea of the minimum age of any particular individual. The term minimum age is used because there could be additional leaves that are not visible and therefore not counted.

Determining the age of a Johannesteijsmannia is unusually problematic. The acaulescent habit, short internodes, and overlapping leaf bases that are not easily distinguishable, are drawbacks in attempting to age this umbrella leaf palm. Since the number of individuals in each plot is not huge and the species is under threat, the excavation of a few individuals in order to assess the leaf base number was not in favor. Hence, no attempts were made to determine the age structure of this species at this stage, and this requires further observation.

Slow growth rates of trees in dipterocarp forests are not unusual. Manokaran and Kochummen (1987) demonstrated a slow growth in more than $50 \%$ of trees ( $>10 \mathrm{~cm} \mathrm{DBH})$ at Sungei Menyala FR and Pasoh FR, which have a similar environment to Angsi FR. They found that $95 \%$ of the fastest growing individuals were canopy species and the shade-tolerant under story species have the slowest growth rates. Consequently, low rates of tree growth represent a low rate of forest regeneration. However, in the wild, it is common for the growth rates to be slower than that of cultivated plants. Nutrients or soil minerals play a major role in enhancing the growth, and in the wild, a lack of soil nutrients and irregular water supply may slow the growth of J. lanceolata.
Johnson (1996) has classified this plant as under threat and it is quite alarming to see this genus being sold widely in plant nursery in the country, without knowing its source. A casual conversation with a group of Orang Asli (indigenous tribe) men revealed that there are people who have asked them to collect the young plants of this genus from the depth of the jungle.

The data presented here might create awareness that this species is already a slow growing plant and in order to inhibit further negative impact such as it becoming endangered or extinct, some form of regulation or public awareness needs to be imposed.

\section{ACKNOWLEDGEMENTS}

The authors would like to thank the Ministry of Science, Technology and Environment of Malaysia for the grant IRPA 09-02-03-0659, to Forestry Department Negeri Sembilan for letting us setting up the study plot in the area, to $\mathrm{Mr}$. Cha for field assistance, to Prof Wong Khoon Meng for plant identification and to Mr. L. Renshaw for reading the manuscript.

\section{REFERENCES}

Bullock, S.H. 1980. Demography of an undergrowth palm in littoral Cameroon. Biotropica 12:247-255.

Clancy, K.E. and M.J. Sullivan. 1990. Demography of the needle palm, Rhapidophyllum hystrix in Mississippi and Alabama. Principes 34:64-78.

De Steven, D., D.M. Windsor, F.E. Putz and B. De Leon. 1987. Vegetative and reproductive phenologies of a palm assemblage in Panama. Biotropica 19:432-356.

Dransfield, J. 1972. The genus Johannesteijsmannia H.E. Moore Jr. Gardens' Bulletin Singapore 26:63-83. 
Holttum, R.E. 1955. Growth habits of monocotyledons variations on a theme. Phytomorphology 5:399-413.

Johnson, D. 1996. Palms, Their Conservation and Sustained Utilization. (ed.) IUCN, Gland, Switzerland and Cambridge, UK.

Kikuzawa, K. 1989. Ecology and evolution of phenological pattern, leaf longevity and leaf habit. Evol. Tends Plant 3:105-110.

Manokaran, N. and K.M. Kochummen. 1987. Recruitment, growth and mortality of tree species in a lowland dipterocarp forest in peninsular Malaysia. Journal of Tropical Ecology 3:315-330.
Rozainah, M.Z., J. Dransfield and M. Keith-Lucas. 2000. The demography of two wild Arenga species (Arecaceae) in Malaysia. Mal. Nat. Journal 5(2):95-107.

Sarukhan, J. 1978. Studies on the demography of tropical trees. In: Tropical Trees as Living System. (eds.) Tomlinson, P.B. and M.H. Zimmermann. Cambridge University Press, New York.

Tomlinson, P.B. 1979. Systematics and ecology of the palmae. Ann. Rev. Ecol. Syst. 10:85-107.

Uhl, N.W. and J. Dransfield. 1987. Genera Palmarum. Alien Press, Lawrence, Kansas. 